\title{
Nonoperative treatment of closed displaced midshaft clavicle fractures
}

\author{
Cesare Faldini - Matteo Nanni - Danilo Leonetti • \\ Francesco Acri · Claudio Galante - Deianira Luciani • \\ Sandro Giannini
}

Received: 20 March 2010/ Accepted: 23 September 2010/Published online: 9 October 2010

(C) The Author(s) 2010. This article is published with open access at Springerlink.com

\begin{abstract}
Background Closed displaced midshaft clavicle fractures used to be treated nonoperatively, and many studies have reported that nonoperative treatment gave good results. However, more recent studies have reported poorer results following nonoperative treatment, whereas the results of operative treatment have improved considerably. The aim of this paper was to report the results of treating closed displaced midshaft clavicle fractures nonoperatively.

Materials and methods One hundred Edinburgh type 2B clavicle fractures (69 type 2B1 and 31 type 2B2) in 100 patients ( 78 males and 22 females) aged between 18 and 67 years (mean 32 years) were treated. All patients were treated using a figure-of-eight bandage. Clinical and radiographic assessment was performed at the time of trauma, 1, 2 and 3 months after the trauma, and then at an average follow-up of 3 years (range 1-5 years). The outcome was rated at the last follow-up using the DASH score. Results Ninety-seven of the 100 fractures healed. Three nonunions were observed. Average healing time was 9 weeks (range 8-12 weeks). No statistically significant correlation between the type of fracture and the healing time was observed. The average DASH score was 24 (range 0-78) and, based on this score, 81 patients presented excellent results, 12 good, 5 fair, and 2 poor. No statistically significant correlation between the type of the fracture and the score was observed.
\end{abstract}

C. Faldini $(\varangle) \cdot$ M. Nanni $\cdot$ D. Leonetti $\cdot$ F. Acri .

C. Galante · D. Luciani - S. Giannini

Department of Orthopaedic Surgery, University of Bologna,

Istituto Ortopedico Rizzoli, Via G.C. Pupilli 1,

40136 Bologna, Italy

e-mail: cesare.faldini@ior.it
Conclusions We believe that nonoperative treatment is still appropriate in most cases, as it yields good results without incurring the potential complications of surgery.

Keywords Clavicle $\cdot$ Midshaft fractures ·

Displaced fractures $\cdot$ Nonoperative treatment

\section{Introduction}

The clavicle provides the junction between the chest and the upper limb, so it plays an important role in the whole function of the shoulder girdle. Morphologically, the clavicle normally presents a characteristic S-like shape resulting from the junction of two opposite curves at the level of the midshaft. The bone is thinner and consequently weaker at this junction, which is why most fractures occur at this level [1-3].

Fractures of the clavicle are common, and account for $2-15 \%$ of all adult fractures and $33-45 \%$ of all injuries involving the shoulder girdle $[1,4-6]$. The midshaft is the most frequently affected site, encompassing $69-82 \%$ of all clavicle fractures, and most fractures that occur in the midshaft are displaced [1, 2]. The literature reports two peaks of incidence: the first (and largest) is associated with young active males, whereas the second is associated with elderly individuals, with a slight female predominance $[2,4,7]$.

Clavicle fractures are often a consequence of direct trauma (e.g., a fall) to the shoulder, where the force typically propagates along the axis of the clavicle from the acromioclavicular to the sternoclavicular joint [8]. Clinical aspects of clavicle fractures typically include pain over the site of the lesion, with visible deformity of the bone's profile due to the downward displacement of 
the lateral fragment under the weight of the shoulder and the upward displacement of the medial fragment due to the action of the sternocleidomastoid muscle. The diagnosis of clavicle fracture is usually confirmed by an anteroposterior view radiograph. Functional impairment of the shoulder and the upper limb can be extremely variable; nevertheless, the whole limb should be carefully evaluated, especially to exclude associated lesions involving the brachial plexus or the subclavian vessels, even though this kind of injury is rare [9, 10]. A careful clinical and radiographic assessment is also necessary to exclude associated chest injuries, such as pneumothorax or hemothorax, which are reported in the literature to occur at rates of up to $3 \%[1,11]$.

In the past few years, various classifications have been proposed for clavicle fractures [12, 13]. The Edinburgh classification [2] was proposed recently and has since been widely accepted. This classifies clavicle fractures according to the anatomical site involved (medial end, midshaft, lateral end), articular involvement (sternoclavicular or acromioclavicular joint), displacement, and extent of comminution (Table 1).

Historically, clavicle fractures used to be treated nonoperatively $[1,13]$. Even for displaced fractures, the literature generally reports a high rate of good results with a low nonunion rate [13-15]. On the other hand, recent studies have reported poorer functional outcomes with nonunion rates of up to $20 \%$ for displaced, comminuted midshaft fractures treated nonoperatively, whereas the results of operative treatment have improved considerably [16-20]. Thus, while there is general agreement that undisplaced clavicle fractures should be treated nonoperatively, the choice of treatment for displaced fractures is still widely debated.

Therefore, the aim of this paper was to report the results of treating 100 closed displaced midshaft clavicle fractures nonoperatively.

\section{Materials and methods}

This study was authorized by the ethical committee of Rizzoli Orthopaedic Institute, and it was performed in accordance with the ethical standards of the 1964 Declaration of Helsinki, as revised in 2000. All patients gave informed consent to participate in this study.

Between 2004 and 2006, 100 clavicle fractures were treated in 100 patients ( 78 males and 22 females). Average age was 32 years (range 18-67 years). None of the patients had sustained a clavicle fracture before. The right side was involved in 68 cases and the left side in the remaining 32 . In 72 cases the fracture affected the dominant limb (Table 2).

All fractures were due to a high-energy trauma: a road accident in 48 cases, a sporting accident in 22 cases, an accident at work in 18 cases, and a domestic accident in 12 cases. All patients came to our emergency room, where they were clinically and radiographically evaluated. Clinically, an altered clavicle profile with a palpable prominence of the fractured bone was present, associated with pain and swelling around the site of the fracture, and with variable functional impairment. The function of the shoulder girdle-particularly in relation to the sternoclavicular and the acromioclavicular joints-was carefully evaluated, as well as the function of the whole upper limb, principally to exclude potential neurologic or vascular lesions. Patients presenting associated injuries, open clavicular fractures and neurologic or vascular lesions were excluded from this series.

Radiographic evaluation was performed with standard radiographs. All of the patients considered in this series presented a displaced midshaft clavicle fracture of type $2 \mathrm{~B}$ according to the Edinburgh classification [2]. Sixty-nine fractures were classified as type $2 \mathrm{~B} 1$ and 31 as type $2 \mathrm{~B} 2$.

A figure-of-eight bandage was applied in all cases (Fig. 1), and radiography was performed after applying the
Table 1 The Edinburgh classification of clavicle fractures

\begin{tabular}{|c|c|c|}
\hline \multirow[t]{4}{*}{ Type 1 medial-end fracture } & 1 A-undisplaced & 1 A 1 - extra-articular \\
\hline & & 1 A 2 -intra-articular \\
\hline & $1 \mathrm{~B}$-displaced & $1 \mathrm{~B} 1$ - extra-articular \\
\hline & & 1 B 2 -intra-articular \\
\hline \multirow[t]{4}{*}{ Type 2 shaft fracture } & $2 \mathrm{~A}$-cortical alignment & 2 A 1 -undisplaced \\
\hline & & 2 A 2 -angulated \\
\hline & $2 \mathrm{~B}$-displaced & 2 B 1 -simple or wedge comminuted \\
\hline & & 2 B 2-isolated or comminuted segmental \\
\hline \multirow[t]{4}{*}{ Type 3 lateral-end fracture } & $3 \mathrm{~A}$-cortical alignment & 3 A 1 - extra-articular \\
\hline & & 3 A 2 -intra-articular \\
\hline & $3 \mathrm{~B}$-displaced & 3 B 1 -extra-articular \\
\hline & & 3 B 2-intra-articular \\
\hline
\end{tabular}


Table 2 Demographic data of the series considered in this study

\begin{tabular}{|c|c|c|c|c|c|c|c|}
\hline & \multirow[t]{2}{*}{ Patients } & \multirow[t]{2}{*}{ Average age } & \multicolumn{2}{|c|}{ Type of fracture } & \multicolumn{2}{|c|}{ Side involved } & \multirow[t]{2}{*}{ Dominant limb involvement } \\
\hline & & & 2 B 1 & 2 B 2 & Right & Left & \\
\hline Males & 78 & $32(18-67)$ & 52 & 26 & 54 & 24 & 58 \\
\hline Females & 22 & $31(20-51)$ & 17 & 5 & 14 & 8 & 14 \\
\hline Total & 100 & $32(18-67)$ & 69 & 31 & 68 & 32 & 72 \\
\hline
\end{tabular}

bandage in order to check the alignment of the fragments. Patients were taught about the correct use of the bandagein particular, how to maintain its proper position and avoid axillary pressure sores and compression of the neurovascular bundle - and active movements of the elbow and the hand were prescribed. All patients were finally discharged and then monitored as outpatients.

For each patient, clinical and radiographic assessments were performed at 1,2 and 3 months after the trauma, and then at the last available follow-up. Four of the authors (MN, DL, FA, CG), who were not directly involved in the treatment, independently evaluated each radiograph. Afterwards, each evaluation was compared with the evaluations performed by the other observers. When there were differing opinions among the four observers, a combined assessment was performed and agreement was reached. The figure-of-eight bandage was maintained all of the time until radiographic evidence of callus formation. During this period, shoulder movements were forbidden, while active movements of the elbow (flexion-extension), of the forearm (pronation-supination), of the wrist (flexion-extension), and of the hand were prescribed in order to prevent contractures (particularly in flexion of the elbow and pronation of the forearm) and peripheral edema. Also, isometric deltoid exercises were advised in order to preserve the tone of the muscle (phase 0). After radiographic evidence of callus, the patients were encouraged to perform mild, progressive, passive (with the help of a physiotherapist) and active mobilization of the injured shoulder girdle-without resistance and according to pain-in all planes, avoiding maximal range of motion in abduction, adduction, and rotations. Also, they were invited to gradually remove the figure-of-eight bandage (phase 1). After radiographic evidence of bone bridging at the fracture site, the bandage was completely removed and physiotherapy for the upper limb was prescribed, with active full range of motion and resistance exercises of the shoulder (phase 2).

The fracture healing was assessed via both clinical and radiographic parameters: absence of pain or tenderness on palpation at the site of the fracture, recovered motion of the shoulder girdle without pain, and radiographic evidence of bone continuity with obliteration of the fracture line. Once the healing of the fracture had been clinically and radiographically assessed, a complete physiotherapy program
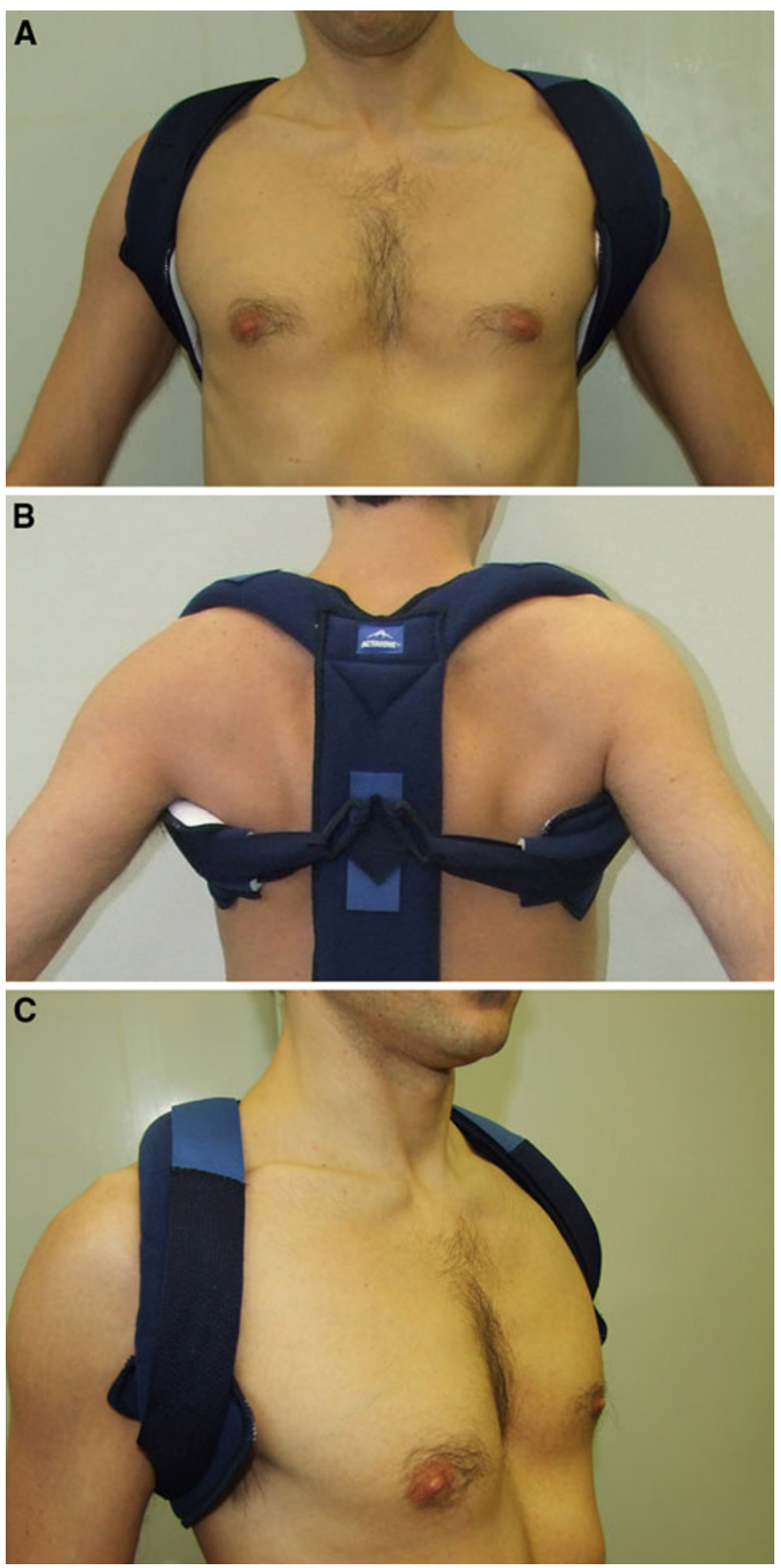

Fig. 1 Figure-of-eight bandage. a Anterior and b posterior aspects. c An altered bone profile due to the fracture is noticeable

including active movements and muscle strengthening was prescribed in order to progressively regain the complete function of the shoulder girdle (phase 3). 
All patients were finally checked at an average followup of 3 years (range 1-5 years) after trauma. At the last follow-up, the clinical evaluation was repeated and four of the authors (MN, DL, FA, CG) independently rated the outcome using the DASH (disabilities of the arm, shoulder and hand) score [21] (Table 3).

For each patient, we noted the healing time of the fracture, the clinical score at last follow-up, the time taken before they resumed their previous daily activities, job, or sport, and any complaints. We evaluated whether there was a correlation between the type of the fracture and the healing time using Spearman's rho, and whether there was a correlation between the type of the fracture and the functional outcome at follow-up using the chi-square test. For all tests, $P<0.05$ was considered significant. Data analysis was performed using the Statistical Package for the Social Sciences (SPSS) ${ }^{\circledR}$ software, version 9.0 (SPSS Inc., Chicago, IL, USA).

\section{Results}

Ninety-seven of the 100 fractures healed. Three nonunions were observed. Excluding cases of nonunion, the average fracture healing time was 9 weeks (range 8-12 weeks; Fig. 2). No statistically significant correlation between the fracture type and the healing time was observed. Variable residual prominence of the bone profile associated with a slight shortening of the clavicle was noticeable in all cases.

The average DASH score was 24 (range 0-78) and, based on this score, 81 patients presented excellent clinical results, 12 good, 5 fair, and 2 poor. No statistically significant correlation between the type of the fracture and the score was observed.

At last follow-up, 77 patients did not complain of any pain, while 23 referred to occasional pain, particularly after prolonged activity. Eighty-one patients presented complete or almost complete function of the shoulder girdle, while 19 presented slight restriction of function. Two patients complained of a loss of strength in the injured shoulder.

Patients resumed their daily activities after an average of 6 weeks (range 5-7 weeks) from the trauma, and their original work activities after an average of 7 weeks (range 6-8 weeks) from the trauma for sedentary jobs and an average of 10 weeks (range 9-12 weeks) for strenuous jobs. Patients who practiced sports resumed their activities after an average of 10 weeks (range 9-11 weeks) following the trauma. Eighty-one patients did not report any limitation in their performance of daily activities, 17 reported mild limitation, and two reported moderate limitation. No difficulty in performing work activities was reported by 77 patients, mild difficulty was reported by 21 patients, and severe difficulty was reported by two patients, who had to reduce their workloads.

Regarding aesthetic concerns, seven female patients complained about the presence of the residual bone prominence, whereas no complaints were reported by male patients. None of the patients underwent further treatment, even in the cases with failed fracture healing.

\section{Discussion}

Traditionally, the treatment of clavicle fractures has been nonoperative $[1,13]$. Until recently, the literature reported a high rate of good outcomes with a low rate of nonunions following nonoperative treatment, and there was no evidence of functional benefits resulting from surgery in comparison with nonoperative treatment $[1,13,22,23]$. Nevertheless, many authors have recently suggested operative treatment for clavicle fractures, particularly in the case of high displacement or comminution, and have reported lower rates of nonunion and better functional outcomes for operative treatment [16-18, 20].

Based on the results of this study, we believe that the treatment of displaced midshaft clavicle fractures should account for various factors, including not only the clinical and radiographic aspects of the fracture but also the characteristics of the patient, such as their general clinical condition, their compliance with the treatment, their functional requirements and their expectations. Nonoperative treatment using a figure-of-eight bandage is simple to carry out. Nevertheless, this device is not able to achieve anatomical reduction of the fracture, and moreover the risk of axillary pressure sores with compression of the neurovascular bundle may produce significant discomfort for the patient. On the other hand, surgical treatment may allow the anatomical reduction of the fracture and sometimes a quicker recovery. However, surgical treatment is associated with many more possible complications [7, 20, 2428]. The main potential surgical complication is a lesion of the subclavian vessels or the brachial plexus. Despite the fact that the risk of this complication is rarely described in the literature $[7,24,26]$, the occurrence of this kind of injury may represent a surgical emergency, requiring the intervention of the vascular surgeon or the neurosurgeon. Furthermore, surgery presents an associated risk of infection, wound-healing complications, and failure of the fixation device. Sometimes, when the patient is young and active, the prospect of an earlier return to work, sport or recreational activity can direct the choice of treatment to surgery. These patients should be properly informed of the risks and the actual possibilities of surgical treatment.

Patients usually respond satisfactorily to self-administrated physiotherapy, without needing specific medical 
Table 3 Disabilities of the arm, shoulder and hand questionnaire

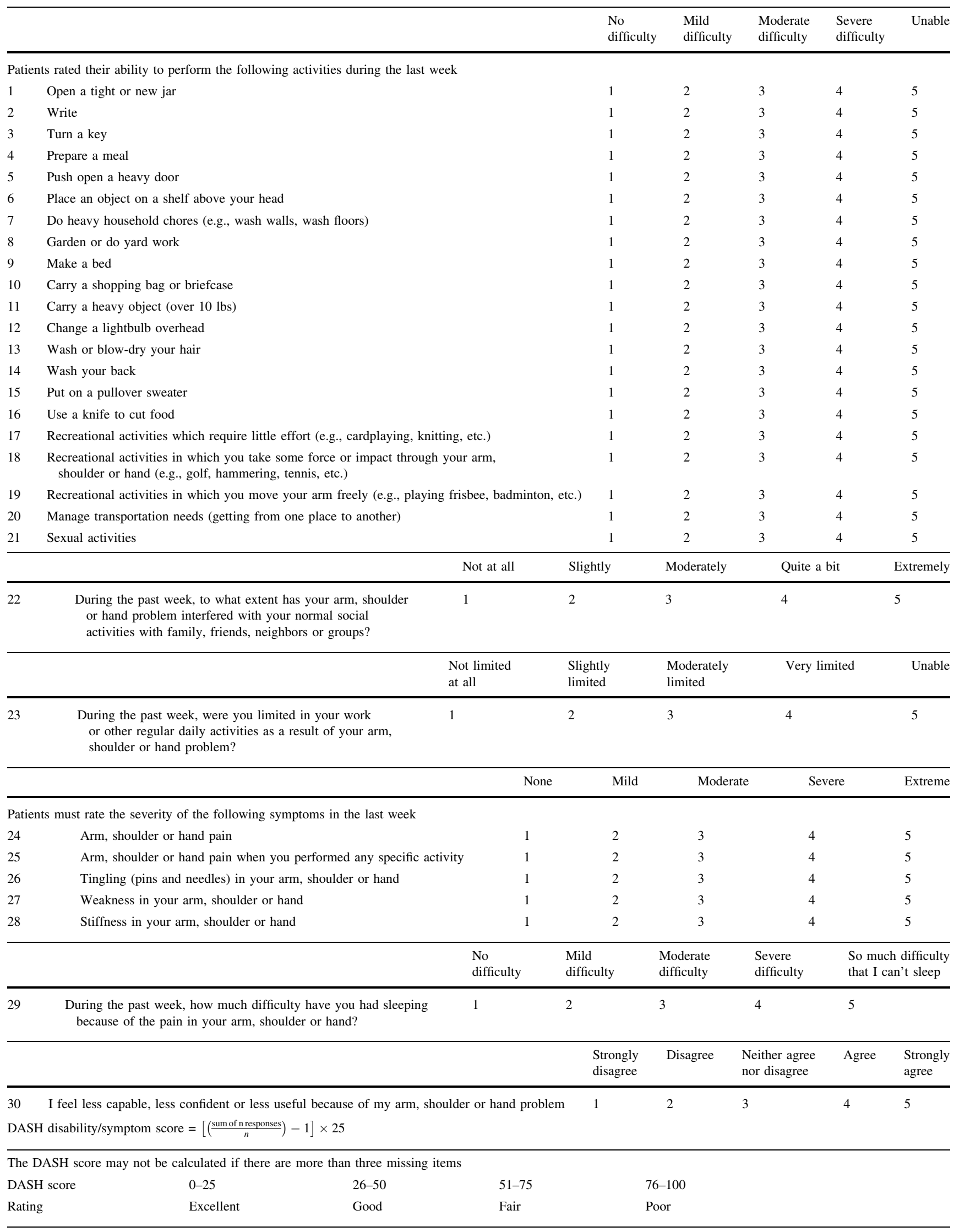



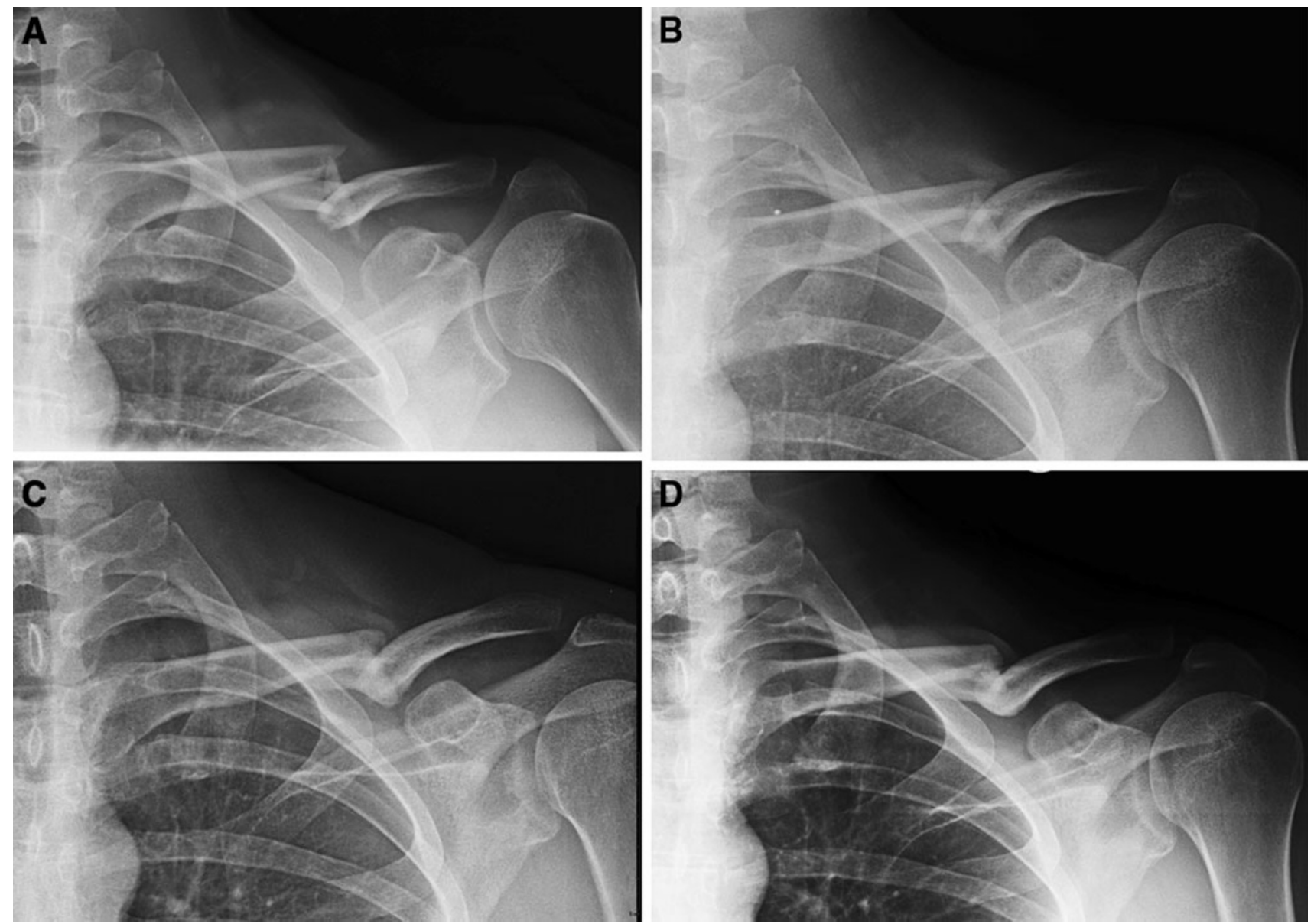

Fig. 2 a Radiographic aspect of an Edinburgh type 2B2 clavicle fracture in a 32 year-old man. b Radiographic aspect of the fracture 1 month after the trauma: callus formation is noticeable. $\mathbf{c}$ Radiograph shows healing of the fracture two months after the trauma.

supervision [7]. When the figure-of-eight bandage is applied, patients are taught about the care they must take to avoid shoulder movements while performing active selfmobilization of the elbow, the wrist and the hand; afterwards, when rehabilitation of the shoulder girdle must be undertaken, patients are initially helped by a physiotherapist (home care or outpatient sessions) and then, once they have been adequately taught the correct exercises to perform, they continue the physiotherapy by themselves. In our series, most of the patients tolerated nonoperative treatment with a figure-of-eight bandage well, they easily completed the rehabilitation program, and they returned early to their previous activities.

The functional consequences of clavicle shortening are controversial [17, 19, 28-30]. Hill et al. [17] reported that unsatisfactory results were significantly associated with a clavicle shortening of $20 \mathrm{~mm}$ or greater. McKee et al. [19] observed a higher prevalence of dissatisfaction and residual disability in patients with a clavicle shortening of greater than $20 \mathrm{~mm}$. Chan et al. [30] suggested a potential

d Radiographic aspect of the clavicle 6 months after the trauma: the fracture has healed and the bone has been remodeled. A residual prominence of the bone profile is noticeable

association between clavicle shortening and shoulder dysfunction. On the other hand, other authors have reported that permanent post-traumatic shortening of the clavicle has no clinical relevance. Judd et al. [28], in a comparison study between operative and nonoperative management of clavicle fractures, did not observe a significant difference between late functional outcome of patients with a clavicle shortening of greater than $20 \mathrm{~mm}$ and late functional outcome of patients with a clavicle shortening of less than $20 \mathrm{~mm}$. Nordqvist et al. [29], in a 5-year follow-up study, affirmed that permanent shortening of the clavicle has no clinical significance, even though it is common after a fracture. Despite the fact that the healing of the fractures in our series always occurred with some degree of angulation and slight shortening of the clavicle, most patients did not complain of any functional limitation, and they tolerated the residual bone prominence well (Fig. 3).

The main limitation of this study relates to patient selection, since we considered a series of patients with a wide range of ages, and we are aware that the healing time 

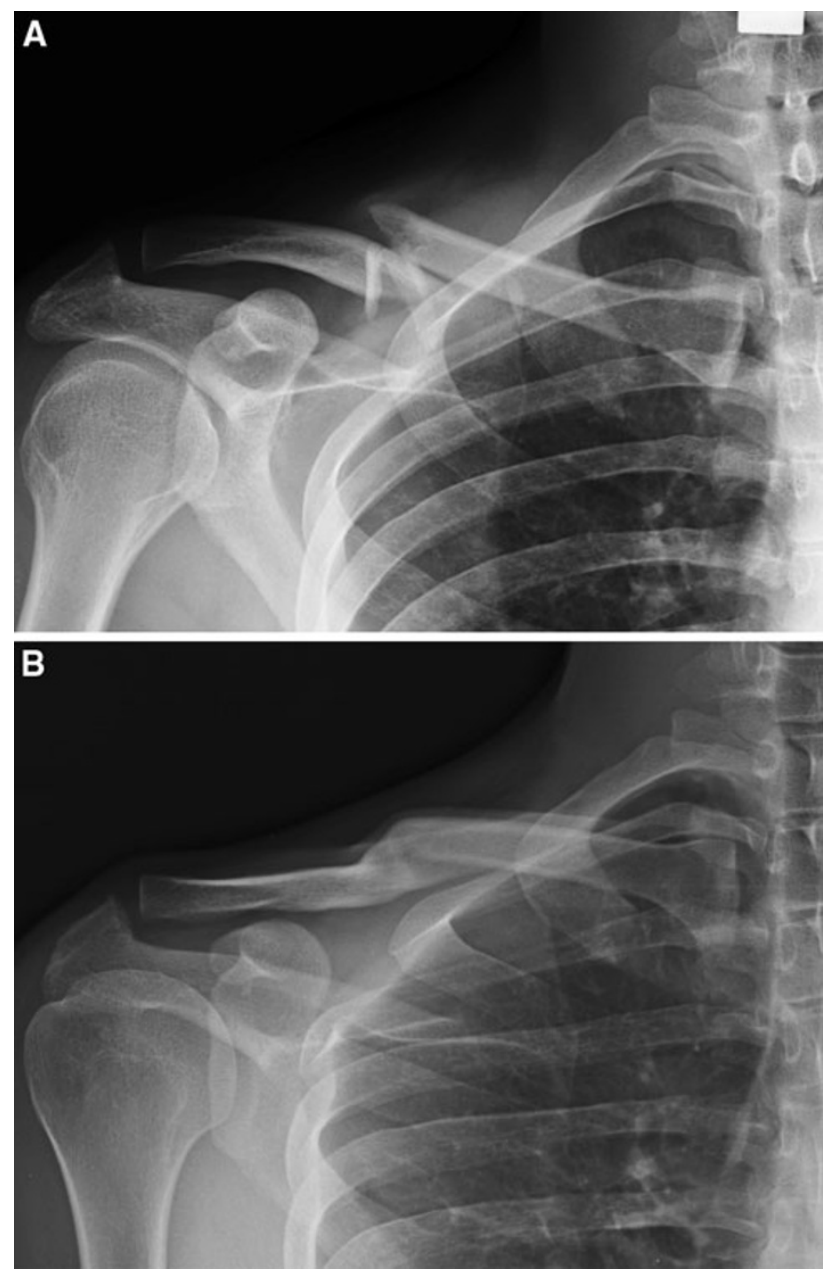

Fig. 3 a Radiographic aspect of an Edinburgh Type 2B2 clavicle fracture in a 28 year-old male, and $\mathbf{b}$ radiographic aspect at 2 year follow-up: the fracture has healed with evident bone remodeling. Even though a slight shortening of the clavicle is noticeable, no functional impairment was mentioned by the patient at last follow-up

of a fracture, as well as functional requirements, can vary greatly between younger and older patients. Furthermore, we rated the functional outcome using a score that does not include objective shoulder function parameters, such as strength and range of motion.

In conclusion, while we are aware that the treatment of closed displaced midshaft clavicle fractures is still debated in the literature, we believe that nonoperative treatment is still appropriate in most cases, as it yields results that are as good as those achieved through surgical treatment in terms of bone healing, functional outcome and patient satisfaction, but without the potential complications of surgery. Therefore, we recommend surgical treatment for closed displaced midshaft clavicle fractures only when vascular or neurologic complications are in progress, thus representing a surgical emergency.

\section{Conflict of interest None}

Open Access This article is distributed under the terms of the Creative Commons Attribution Noncommercial License which permits any noncommercial use, distribution, and reproduction in any medium, provided the original author(s) and source are credited.

\section{References}

1. Rowe CR (1968) An atlas of anatomy and treatment of midclavicular fractures. Clin Orthop 58:29-42

2. Robinson CM (1998) Fractures of the clavicle in the adult. Epidemiology and classification. J Bone Joint Surg Br 80:476-484

3. Havet E, Duparc F, Tobenas-Dujardin AC, Muller JM, Delas B, Freger P (2008) Vascular anatomical basis of clavicular nonunion. Surg Radiol Anat 30:23-28

4. Nordqvist A, Petersson C (1994) The incidence of fractures of the clavicle. Clin Orthop 300:127-132

5. Nowak J, Holgersson M, Larsson S (2000) The aetiology and epidemiology of clavicular fractures. A prospective study during a two-year period in Uppsala, Sweden. Injury 31:353-358

6. Postacchini F, Gumina S, De Santis P, Albo F (2002) Epidemiology of clavicle fractures. J Shoulder Elbow Surg 11:452-456

7. Kashif Khan LA, Bradnock TJ, Scott C, Robinson CM (2009) Fractures of the clavicle. J Bone Joint Surg Am 91:447-460

8. Stanley D, Trowbridge EA, Norris SH (1988) The mechanism of clavicular fracture: a clinical and biomechanical analysis. J Bone Joint Surg Br 70:461-464

9. Yates D (1976) Complications of fractures of the clavicle. Injury 7:189-193

10. Barbier O, Malghem J, Delaere O, Vande Berg B, Rombouts JJ (1997) Injury to the brachial plexus by a fragment of bone after fracture of the clavicole. J Bone Joint Surg Br 79:534-536

11. Dugdale TW, Fulkerson JP (1987) Pneumothorax complicating a closed fracture of the clavicle. A case report. Clin Orthop Relat Res 221:212-214

12. Allman FL Jr (1967) Fractures and ligamentous injuries of the clavicle and its articulation. J Bone Joint Surg Am 49:774-784

13. Neer CS II (1968) Fractures of the distal third of the clavicle. Clin Orthop Rel Res 58:43-50

14. Stanley D, Norris SH (1988) Recovery following fractures of the clavicle treated conservatively. Injury 19:162-164

15. Nordqvist A, Petersson CJ, Redlund-Johnell I (1998) Mid-clavicle fractures in adults: end result study after conservative treatment. J Orthop Trauma 12:572-576

16. Mullaji AB, Jupiter JB (1994) Low-contact dynamic compression plating of the clavicle. Injury 25:41-45

17. Hill JM, McGuire MH, Crosby LA (1997) Closed treatment of displaced middle-third fractures of the clavicle gives poor results. J Bone Joint Surg Br 79:537-539

18. Zlowodzki M, Zelle BA, Cole PA, Jeray K, McKee MD (2005) Evidence-based orthopaedic trauma working group. Treatment of acute midshaft clavicle fractures: systematic review of 2144 fractures: on behalf of the Evidence-Based Orthopaedic Trauma Working Group. J Orthop Trauma 19:504-507

19. McKee MD, Pedersen EM, Jones C, Stephen DJ, Kreder HJ, Schemitsch EH, Wild LM, Potter J (2006) Deficits following nonoperative treatment of displaced midshaft clavicular fractures. J Bone Joint Surg Am 88:35-40

20. Canadian Orthopaedic Trauma Society (2007) Nonoperative treatment compared with plate fixation of displaced midshaft clavicular fractures. J Bone Joint Surg Am 89:1-10 
21. Hudak PL, Amadio PC, Bombardier C (1996) Development of an upper extremity outcome measure: the DASH (disabilities of the arm, shoulder, and hand). The upper extremity collaborative group (UECG). Am J Ind Med 29:602-608

22. Zenni EJ Jr, Krieg JK, Rosen MJ (1981) Open reduction and internal fixation of clavicular fractures. J Bone Joint Surg Am 63:147-151

23. Robinson CM, Court-Brown CM, McQueen MM, Wakefield AE (2004) Estimating the risk of non-union following nonoperative treatment of a clavicular fracture. J Bone Joint Surg Am 86:1359-1365

24. Freeland A (1990) Unstable adult midclavicular fracture. Orthopedics 13:1279-1281

25. Bostman O, Manninen M, Pihlajamaki H (1997) Complications of plate fixation in fresh displaced midclavicular fracture. J Trauma 43:778-783
26. Ring D, Holovacs $\mathrm{T}$ (2005) Brachial plexus palsy after intramedullary fixation of a clavicular fracture. J Bone Joint Surg Am 87:1834-1837

27. Jeray KJ (2007) Acute midshaft clavicular fracture. J Am Acad Orthop Surg 15:239-248

28. Judd DB, Pallis MP, Smith E, Bottoni CR (2009) Acute operative stabilization versus nonoperative management of clavicle fractures. Am J Orthop J 38:341-345

29. Nordqvist A, Redlund-Johnell I, Von Scheele A, Petersson CJ (1997) Shortening of clavicle after fracture. Incidence and clinical significance, a 5-year follow-up of 85 patients. Acta Orthop Scan 68:349-351

30. Chan KY, Jupiter JB, Leffert RD, Marti R (1999) Clavicle malunion. J Shoulder Elbow Surg 8:287-290 